\title{
IDIOPATHIC STEATORRHOEA
}

\author{
Clifford F. Hawkins, M.D., F.R.C.P. \\ Consultant Physician, United Birmingham and Mid-Worcestershire Hospitals; Lecturer in Clinical Medicine, University of \\ Birmingham
}

A NEW chapter in the story of idiopathic steatorrhœa was opened by the discovery of the various biopsy tubes which are swallowed by the patient and take either single specimens from the duodenum or jejunum (Shiner, 1956; Crossby and Kugler, 1957) or, more recently, retrieve several samples from any level in the small bowel (Brandborg, Rubin and Quinton, 1959; Baker and Hughes, 1960). This allows more exact diagnosis and increases the chance of separating idiopathic steatorrhœa from the numerous disorders of the small gut which can cause an identical pattern of symptoms and nutritional effects; it also enables study of the intestinal cell with the electron microscope and by histochemical methods.

The main clinical features have been well defined (see Fig. I), but the nomenclature threatens to become as protean as its symptoms. The name of a disease is seldom satisfactory and is often a target for criticism, particularly as advancing knowledge sheds new light on the ætiology, or new treatment becomes effective. The defect of absorption involves all nutrients including fats, protein, carbohydrates, vitamins, minerals and water; so that the term steatorrhoa is too limited in outlook. 'Primary malabsorption syndrome' is the diagnosis preferred in the United States, a label which runs the risk of abbreviation to P.M.S. Many, however, would regard malabsorption as too limitless a term; not only might pernicious anæmia be an example of the primary malabsorption syndrome, but this could include diseases with increased absorption as of iron in hæmachromatosis. Non-tropical sprue may imply too close an association with tropical sprue, and the cause is almost certainly quite different. Adult cœliac disease is certainly true for many patients; but the future may show different causes for others. Similarly, it is too soon to change to the term gluten-induced enteropathy. Many are dramatically cured by withdrawal of gluten but others, with an indistinguishable clinical picture, are not; nor is it known whether the gluten sensitivity is the primary cause of the disease, or a secondary phenomenon. So, for the present, 'idiopathic steatorrhœa' will suffice; the term 'steatorrhœa' emphasises the common denominator of this

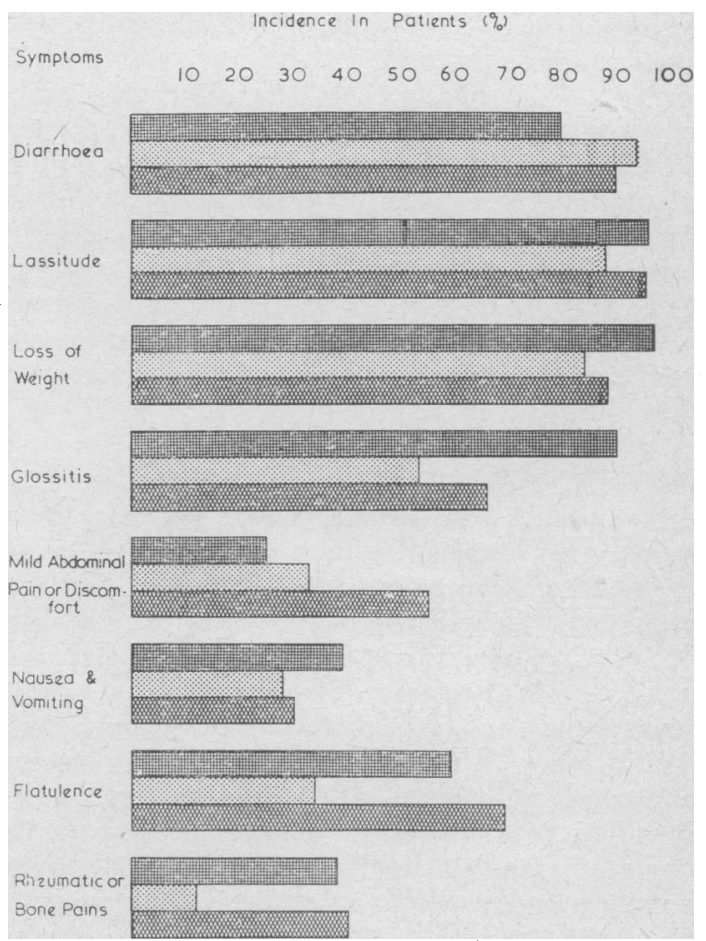

FIG. I.-A comparison of the main symptoms occurring in three different series of patients:

Upper row from Cooke, Peeney and Hawkins (I953).

Middle row from Bossak, Wang and Adlersberg (I957).

Lower row from Green and Wollaeger (I959).

versatile syndrome, and the prefix 'idiopathic' underlines our ignorance of its cause.

\section{Diagnosis}

Idiopathic steatorrhœa occurs about equally in men and women and most commonly presents between the age 40 and 45 years; about onethird give a history of probable coeliac disease in childhood. Diarrhœa is a presenting complaint from 43 to $73 \%$ (Cooke, Peeney and Hawkins, 1953; Green and Wollaeger, 1958) and usually starts slowly but sometimes more abruptly. An 
observant person may have been surprised at the change in colour of the stools, or astonished at their gargantuan size; or noticed them floating, this being due to fat or fermentation. Some, however, may have become accustomed to longstanding mild diarrhœa and misleadingly reply ' yes ' to the question, ' are your bowels normal? '; further questioning reveals a bowel action of three or four times daily with occasional episodes of looseness. Others have no disturbance of their bowels or may even be costive. In more than half of the cases, the symptoms of ill-health with anæmia, glossitis, malaise, and loss of weight, so dominate the picture that the diarrhœa can be overlooked. As awareness of a disease increases, so the diagnosis is made earlier and the clinical picture altered. It can be misleading if the image in the physician's mind is that of a late case with wasting, pigmentation, clubbed fingers, anæmia, and a pellagroid rash; for many patients diagnosed today have no abnormal physical signs and would easily pass an insurance examination, for what that is worth ...

\section{Screening Tests}

A suitable test would enable patients to be selected for fæcal fat studies, or might even avoid the need of this tedious investigation. The large number of test substances such as butter fat, olive oil, glycine, vitamin A and sugars is a sign that none carries the stamp of certainty. New tests seem to have a definite pattern of behaviour. Early studies show a nice distinction between normal and abnormal results, then, in later reports, an insidious overlap seems to develop between the two groups so that the test loses its value. Variable results are not surprising when a natural food such as glucose, is used; for blood levels, in an oral tolerance test, are the result of multiple and complex factors. A flat curve can, alone, never prove that the substance is not absorbed, for it may mean rapid deposition in the stores or slower but complete absorption over a longer period, or rapid excretion in the urine. The glucose tolerance test should be abandoned in the routine diagnosis of idiopathic steatorrhœa, as flat curves are by no means the rule (Cooke and others, 1953), and flat curves may occur in about $40 \%$ of normals (Moyer and Womack, 1950; Gardner, 1956). It may be of help in distinguishing between this and pancreatic steatorrhœa, as high curves are often seen in the latter (Gaddie, Thomas, Smith and French, 1957). The xylose excretion test is more reliable. Although xylose is not so metabolically inactive as was originally thought, its usefulness is shown in several reports (Benson, Culver, Ragland, Jones, Drummey and Bougas, 1957; Christiansen, Kirsner and Ablaza, 1959; Fowler and Cooke, 1960). The xylose in a five-hou specimen of urine is estimated following the ingestion of $25 \mathrm{~g}$. of D-xylose. Normals excrete between 4 and $7 \mathrm{~g}$., whereas patients with idio $\overrightarrow{F^{*}}$ pathic steatorrhœa usually excrete less than $3 \frac{\text { g }}{\text { f }}$ Some workers give 5 instead of $25 \mathrm{~g}$. and obtain results as accurate (Santini, Sheehy and Martine 196I). The test is misleading in patients over $6 \overline{6}$ years but is helpful in distinguishing idiopathic steathorrhœa from other types, such as pancreatice disease, Crohn's disease, or following gastri $\vec{\oplus}$ operations, in which it is usually negative. Ant abnormal test is indicative of disease of thy jejunum.

Some (Wenger, Kirsner and Palmer, 1957) fing the serum-carotene level of help in diagnosis. Carotene, or provitamin $\mathrm{A}$, is a slowly absorbed fat-soluble material present in food such as liveru kidney, carrots and lettuce. It is converted to vitamin $A$ by the mucosa of the small intestines Fasting vitamin A levels are too variable to be o $\$$ value. Estimation of serum carotene is by simple. spectrophotometric technique (Yudkin, I94I) and normal values vary between 60 to $200 \mu \mathrm{g}$. per 108 $\mathrm{ml}$. Low levels occur in high fever, liver disease and if the patients are not eating adequately, bu the levels in idiopathic steatorrhœa are particulfofly low and often less than $20 \mu \mathrm{g}$. per $100 \mathrm{ml}$.

\section{Radiology}

The flocculation pattern, an artefact due t\& clumping of routine barium sulphate, probabl from excess mucus (Ardran, French and Mucklow 1950) is seen in 86 to $90 \%$ of patients (Green an $\$$ Wollaeger, 1959; Cooke and others, 1953) and its presence is a strong indication to investigate the patient for steatorrhœa. Clumping usually occurs: quite soon, and often in the first hour; it should be considered critically after the first one-and-a-half hours as this may sometimes happen in normals?. Flocculation does occur in other types of steatorrhœa such as pancreatic or Crohn's disease but is very unusual.

A non-flocculating solution of barium should be used to outline the mucosa and bowel wall so tha? structural diseases such as Crohn's disease, diver $\rightarrow$ ticulitis, or stricture, can be excluded. In idio음 pathic steatorrhœa, the bowel is strikingly dilated and may mimic intestinal obstruction. This particularly involves the jejunum (Marshak ando Eliasoph, 1957) and is less common in the ileum N The normal feathery pattern due to the crescentic circular folds (plica circulares) has disappearedb and, instead, there is a ladder-like appearance The cause of the dilation is unknown; it may be ${ }^{\text {? }}$ partly a result of the increased fluid contents of the bowel from the defect of water and food absorption? but there is also a lack of tone in the bowel wall 
which results in a slow transit time through the small gut. The commonest error in X-raying the small intestine is to give too large amounts of barium so that overlapping of coils occurs; 6 or $8 \mathrm{oz}$. is enough.

\section{Examination of the Blood}

Most patients have either a macrocytosis or macrocytic anæmia and a blood count is essential. This should include not only an examination of the films and a hæmoglobin estimation but also a redcell count and packed cell volume so that the mean corpuscular volume can be calculated. The typical finding in an anæmia of intestinal origin is the 'dimorphic appearance' on the films due to deficiency of either folic acid or $\mathrm{B}_{12}$, and iron; the mean corpuscular volume will then be above 94 cu. $\mu$ and the mean cell hæmoglobin concentration below $30 \%$. The diagnosis will be missed when an hæmoglobin, which may be between ro and $12 \mathrm{~g}$./ $100 \mathrm{ml}$., only is reported, and when the blood films are examined cursorily by a technician rather than an experienced and interested hæmatologist. The laboratory staff must be trained properly for counting red blood cells. In order to assess the error in the red cell count, 14 samples of blood were divided and sent to the laboratory under fictictious names, unknown to the technicians. The mean difference in the red cell count was $190,000($ S.D. $=0.18)$, and the mean difference in the mean corpuscular volume was $2.82 \mathrm{cu} . \mu$ (S.D.=2.35) (Hawkins and Meynell, 1958).

\section{The Serum Vitamin $B_{12}$ Level}

Serum vitamin $B_{12}$ levels may be diminished and are sometimes as low as in pernicious anæmia. Low readings, in different series of patients, vary between 27 and 50\% (Mollin and Ross, 1954; Meynell, Cooke, Cox and Gaddie, 1957; Doig and Girdwood, 1960). Similarly, there may be malabsorption of radioactive $B_{12}$ and this is usually unaltered by the addition of intrinsic factor (Mollin, Booth and Baker, 1957); but is improved by corticosteroid therapy (Glass, 1956) and the gluten-free diet (Mollin and others, I957). Defective absorption of $\mathrm{B}_{12}$ probably indicates extension of the mucosal lesion to the ileum where it is normally absorbed.

\section{Tests of Absorption using Folic Acid}

Folic acid is probably absorbed in the jejunum (McIntyre, Sachs, Krevans and Conley, I956; Cooke and others, 1957) and defective absorption is an almost invariable and usually persistent event in idiopathic steatorrhœa, often remaining in spite of cure by a gluten-free diet. Girdwood's technique (Girdwood, I953; Doig and Girdwood, 1960) requires the estimation of the urinary output of folic acid in 24-hour specimens of urine, collected respectively after subcutaneous and oral test doses of $5 \mathrm{mg}$. of pteroylglutamic acid. The output in the urine in normals is not very different whether the folic acid is injected or taken by mouth. The excretion index is calculated by the ratio:

Urinary folic acid output after $5 \mathrm{mg}$. orally

Urinary folic acid output after $5 \mathrm{mg}$. subcutaneously $\times 100$

Girdwood (1960) having performed 524 tests, finds that an output of less than $1.5 \mathrm{mg}$. after the oral test dose together with an excretion index of less than $75 \%$ is diagnostic of defective absorption. Both figures were low in II 4 out of 129 patients with the steatorrhœa syndrome. In control subjects, the urinary output after the oral dose ranges from 1.8 to $4.3 \mathrm{mg}$., and the excretion index from 59 to $148 \%$. It may be necessary to 'saturate' the patient with folic acid by four daily intramuscular injections of $15 \mathrm{mg}$. beforehand in certain cases where the injected and oral doses are both low. Occasionally findings indicating malabsorption have been obtained in controls but normal results have been found when the tests have been repeated. The folic acid or rather ' folic acid substances' are measured in the urine by a bioassay method using streptococcus facalis as the test organism. The test compares the effect of folic acid given by two routes and presumably the factors that affect any balance study will be present in each. Other workers have obtained similar results (Butterworth, Nadel, PerezSantiago, Santini and Gardner, 1957; Cox, Maynell, Cooke and Gaddie, r958).

An alternative indirect method of attempting to measure the tissue stores of folic acid is by the rate of clearance of an intravenous dose of $15 \mu \mathrm{g}$. of folic acid/kg. body weight (Chanarin, Mollin and Anderson, 1958). The dose is completely cleared from the blood after ${ }_{5} 5$ minutes in patients deficient in folic acid but not in control subjects. Absorption can also be estimated by measuring the blood levels at one, two and four hours after an oral dose of $3 \mathrm{mg}$. of folic acid (Chanarin, Anderson and Mollin, 1958). Peak concentrations in normals range between 40 and $170 \mu \mathrm{mg}$. of folic acid per $\mathrm{ml}$. of serum and levels below $40 \mu \mathrm{mg}$. are generally found in patients with malabsorption syndromes. Increased clearance from the blood is found also in other conditions such as pregnancy, leukæmia and malignant disease and flat plasma curves following oral folic acid are also present in pregnancy. The assay of serum folic acid, or perhaps more correctly ' folic acid substances', is a difficult one; another technique has recently been described (Herbert, 196r; Waters, Mollin, Pope and Towler, 196r). The discovery of the in- 
creased excretion of formiminoglutamic acid in the urine in states of folic acid deficiency has prompted a biochemical test. This substance (FIGLU), is an intermediate breakdown product of histidine and its urinary excretion is measured after an oral dose of histidine (Spray and Witts, 1959). There should be a greater excretion of FIGLU in folic acid deficiency as compared with normals, but the value of the test is doubtful at the time of writing; positive results occur in liver disease and these are probably due to some metabolic defect other than folic acid deficiency (Carter, Heller, Schaffner and Korn, 1961).

\section{Fejunal Biopsy by the Oral Route}

Satisfactory results depend upon the experience of the person passing the biopsy tube and the availability of one pathologist to interest himself in the specimen; it can be quite useless sending the occasional sample of mucosa with other specimens to the laboratory. Although most cases of idiopathic steatorrhœa are accurately diagnosed without it, jejunal biopsy is essential for any study of this disease, and without it conditions such as Whipple's disease may be missed.

Abnormalities of the mucosa are synonymous with malabsorption, and there is a range of histological changes. The easiest to recognize, and where the observer's error must be slight, is the subtotal villous 'atrophy' (Shiner and Doniach, 1958). The villi are shortened and flattened and may have disappeared altogether, leaving a flat surface. The epithelial cells are characteristically of low cuboidal type and flattened and show nuclei changes. This lesion is usually seen in cœliac disease and in some adult cases. The majority of patients with idiopathic steatorrhœa show less marked changes, the partial villus 'atrophy' (Shiner and Doniach, 1958). Here the villi are shortened and blunted, the crypts of Lieberkuhn are deeper, and the mucosal thickness sometimes increased; and a similar appearance of the villi may occur as an artefact when the biopsies are cut slightly askew rather than exactly perpendicular to the mucosal surface (Rubin, Brandborg, Phelps and Taylor, 1960). This is not specific; it is seen in tropical sprue (Butterworth and Perez-Santiago, 1958) and can result from neomycin therapy (Jacobson, Prior and Faloon, 1960). This group fades into the normal with no dividing line, an event that always creates a large observer's error. The interesting suggestion has been made (Fone, Meynell, Harris, Cooke, Brewer and Cox, 1960) that these two histological types are represented by different clinical patterns; that the first only is diagnostic of adult cœliac disease and that the second group is separate and represents more than one ætiological disorder, the latter often presents suddenly with severe megaloblastic anæmia like tropical sprue. $\frac{3}{\delta}$ Some support to this idea is given by studies $\propto$ using tritium-labelled folic acid (Anderson, $\stackrel{\complement}{\leftarrow}$ Belcher, Chanarin and Mollin, 1960) but the groups cannot be separated by their response to the gluten-free diet as this may occur in either. 등 It has been disappointing to find that the histo- $\frac{\bar{c}}{\overline{\frac{N}{5}}}$. logical appearance of the jejunal mucosa remains $\widehat{\Phi}$ abnormal although the patient may be cured by the gluten-free diet, but Rubin (196I) has reported क obvious improvement and in our patients the $\overrightarrow{0}$ mucosa has sometimes almost reverted to normal. $\overrightarrow{\dot{ }}$ No clue as to the cause of idiopathic steatorrhœa ${ }_{\sigma}$ has so far been obtained either by enzyme studies or electron microscopy. There is often an increased 3 . infiltration in the lamina propria with plasma cells, lymphocytes, and sometimes eosinophils and an. occasional leucocyte, and this may indicate some $\overrightarrow{+}$ reaction to a local noxious stimulus or inflammation, used in its widest sense.

\section{Facal Fat Excretion}

The excretion of excessive fat in the stools is still $\vec{\nabla}$ the cardinal index of dysfunction of the small ${ }^{\circ}$ intestine. Normal subjects excrete about 3 or $4 \mathrm{~g}$. $\frac{\mathbb{O}}{3}$ of fat daily when they eat amounts varying between 50 and $100 \mathrm{~g}$. of fat each day; $95 \%$ of normass excrete less than $7 \mathrm{~g}$. daily on a $150-g$. diet (Annegers, Boutwell and Ivy, 1948). A norma -. ward diet contains about $70 \mathrm{~g}$. of fat daily and the upper limit of fæcal fat can be regarded as 6 or $7 \mathrm{~g}$. daily. The dietary fat need only be controlled by a dietitian when doing special therapeutic studies or, occasionally, in dealing with borderline cases which $\stackrel{\circ}{\bar{Q}}$ may be revealed by increasing the daily amount to $\overrightarrow{\vec{F}}$ Io0 g. or more. All the stools passed during each 24-hour period must be collected for at least $\bar{?}$ three and, in doubtful cases, seven days; and the beginning of the stool collection is often the signal for constipation even in the most diarrhœic 3 . subject. The modern rapid methods of chemicalo: analysis of fat (Kamer, Huinink, Bokkel and Weijers, I949) simplify estimation of fæcal fat, $\stackrel{0}{2}$ but this estimation is still not always the biochemist's delight, unless he has anosmia. Follow-음 up studies of fæcal fat excretion may be needed, $\rightarrow$ particularly in assessing the effect of the gluten-을. free diet. In order to save further hospital ad- N mission special receptacles have been designed by my colleague, Dr. J. M. French; these are cans ${ }^{N}$ that fit exactly into the seat of the lavatory. Six N of these are delivered to the patient, one for eacho day, and after use each lid is sealed by sellotape.o The cans are collected or delivered to the labora- $\bar{\Phi}$ tory at the end of a week and the accuracy of col- $\stackrel{\oplus}{+}$ lection can often be as complete as in a metabolic 0 ward. 
The Value of Radioactive Isotopes in Studying Fat Absorption

Unfortunately, techniques using labelled fats do not carry the accuracy that is often implicit with radioactive isotopes, for the attraction and simplicity of using fats such as triolein labelled with iodine-I3I is obvious. The results of the radioactive triolein test and fæcal chemical balance studies has been compared in 24 normal volunteers and 102 patients with malabsorption (Pimparkar, Tulskey, Kalser and Bockus, I960). In patients with abnormal chemical fats the fæcal radioactivity was abnormal in about $75 \%$, while in those with normal fæcal chemical fat $80 \%$ only had a normal fæcal radioactivity. Blood and urine values are both unsatisfactory because of the overlap between normal and abnormal. This test cannot, therefore, replace the chemical estimation of fat in the stools, and the trouble in collecting the fæces hardly endears it as a simple screening test. Individual fats are absorbed differently in idiopathic steatorrhœa in contrast to normal where there is no qualitative difference, so that labelled fats may be helpful in research. Double tracer techniques can be used to separate idiopathic steatorrhœa from pancreatic steatorrhœa. The absorption of a labelled whole fat such as triolein is compared with a labelled fatty acid like oleic acid; in pancreatic steatorrhœa the absorption of the fat alone is depressed because of failure of digestion, whereas the absorption of both is effected in idiopathic steatorrhœa.

\section{Nutritional and Metabolic Effects Ancria}

The various anæmias illustrate the fact that the nutritional sequelæ may present as separate diseases and the lesion in the bowel can be easily overlooked. One way of finding cases of idiopathic steatorrhœa is to go through the records of patients diagnosed as pernicious anæmia and investigate more fully those where diarrhœa has occurred, where investigation of gastric acidity has been inadequate, and where response to vitamin $B_{12}$ or liver has been incomplete. Addisonian pernicious anæmia and steatorrhœa have been equally responsible in a series of $6 \mathrm{r}$ unselected patients admitted to the General Hospital, Birmingham (Bradley and Cooke, I960). Thirty-one cases were due to pernicious anæmia, 27 to idiopathic steatorrhœa, two resulted from operations on the alimentary tract and one was due to drugs. The more complete the investigations, the less frequent is the diagnosis of pernicious anæmia. The macrocytic anæmia is usually slight and the severe megaloblastic anæmia identical to pernicious anæmia is unusual; the finding of persistently normal values of the blood is strong evidence against the diagnosis of idiopathic steatorrhœa.

A small group, about 10 to $20 \%$, present with iron-deficient anæmia, and idiopathic steatorrhœa should be suspected when no evidence of bleeding is found. This is often refractory to oral iron and is a cause of long-standing iron deficiency with epithelial changes such as koilonychia. Treatment with iron usually results in a macrocytic blood picture.

\section{Hamorrhage}

Bleeding is not due to scurvy, but to vitamin $\mathrm{K}$ deficiency. Skin lesions with purpura or ecchymoses are mostly seen, but there may be massive exsanguinating gastro-intestinal hæmorrhage which can be fatal (Green and Wollaegar, 1959). Epistaxis, bleeding gums, hæmaturia (Ingelfinger, 1943) or menorrhagia may occur, and Badenoch (1960) mentioned two instances of massive retroperitoneal hæmorrhage presenting as acute abdominal emergencies. The prolonged prothrombin time, which is diagnostic, seems to be due to a defect in absorption of vitamin $\mathrm{K}$ rather than increased loss of this in the fatty stools or from liver disease. It is possible that the deficiency may be increased by a low-fat diet giving an inadequate supply of vitamin $\mathrm{K}$, or that a course of antibiotics may precipitate the condition by destroying the intestinal organisms which are said to synthesize the vitamin.

\section{Water and Electrolyte Disturbances}

Nocturnal polyuria may be a troublesome symptom in these patients and frequently occurs during the relapse; the patients comment upon the undisturbed nights that occur as a remission is approached. It can easily be mistaken for the frequency of micturition from urinary infection. Wollaeger and Scribner (I95I) noted the poor diuresis that follows when these patients drink water and suggested that the nocturnal diuresis was due to delayed excretion of water. They postulated that large volumes of water were retained in the small intestine as a compensatory mechanism to dilute the food and facilitate absorption, in a similar way to the increased quantity of water needed to aid excretion in renal failure. To support this hypothesis it was found that fasting abolished nocturnal diuresis. There is, however, a true defect of water absorption, as shown by delayed absorption of heavy water (Reitemeier, Higgins, Lee and Scholer, 1956). This is present in a relapse, but not in a remission and occurs whether or not the patients have taken food. Newsholme and French (1954) have shown a similar delay in the absorption of radioactive sodium. An important practical point is that this 
delayed excretion of water and salt may give a positive Kepler-Power water test and suggests Addison's disease, a result that may easily mislead the clinician, for these patients are often pigmented and hypotensive. Cooke (1957) has pointed out that similar delays in diuresis can be noted in patients with cirrhosis of the liver, congestive cardiac failure, ulcerative colitis and severe hypokalæmia. In any test involving the complex factors concerned in absorption, retention in the body and excretion of a substance like water there may be many factors and the delays in water and sodium absorption may not always be the only ones present in idiopathic steatorrhœa.

\section{Hypokalamia}

Dehydration and syndromes due to sodium or potassium deficiency occur, as in any patients with diarrhœa. It may also happen that low potassium states arise even if the diarrhœa is slight or absent. This follows a prolonged slight negative balance, and unexpected examples of intracellular depletion of potassium can be found in patients who appear well and without dehydration by assessment of the available stores with isotopes (Flear, Cooke and Quinton, 1957). There is an increase in the fæcal potassium; not all of this is due to defective absorption of potassium, for, following an intravenous injection of ${ }^{42} \mathrm{~K}, 20 \%$ was found in the fæces and $80 \%$ in the urine (Cooke, 1957), indicating that fæcal potassium is partly endogenous, probably from the intestinal secretions.

Many patients with idiopathic steatorrhœa may therefore have deficient stores of potassium and the serum levels are not a reliable guide to this (Moore, Edelman, Olney, James, Brooks and Wilson, I957). Unfortunately, the symptoms and signs of the low-potassium syndrome are nonspecific, such as anorexia, nausea and vomiting, muscle weakness with absent tendon reflexes and mental changes. Hypokalæmia may be a factor in causing the dilated coils of bowel seen in idiopathic steatorrhœa, but it is difficult to obtain direct and objective evidence of this in man, although there is experimental evidence of it in dogs (Streeten and Williams, I952). It is often impossible to prove the diagnosis of the lowpotassium syndrome either by the serum levels or electrocardiographic changes, and potassium may have to be given empirically in circumstances where deficiency is likely to be present.

\section{Hypoproteinamia}

Edema of the legs may be a presenting or predominant symptom and anasarca is sometimes seen. Estimation of the serum proteins, the only guide at present to the total body proteins, shows a depression of both albumin and globulin, and $\mathrm{a}^{\circ}$ correlation is found between low levels of serum 3 albumin and the appearance of odema. In one series of 67 patients (Adlersberg, Wang and Bossak, $\stackrel{c}{\Rightarrow}$ I957) the total protein concentration was below吕 $5 \mathrm{~g} . / 100 \mathrm{ml}$. in $19.4 \%$ of patients, in $52 \%$ theo serum albumin level (Biuret method) was belowo $3.5 \mathrm{~g} . / 100 \mathrm{ml}$., and in $23.4 \%$ the level was lower⿳亠口冋. than 2.5 g./ $100 \mathrm{ml}$. Hypocalcæmia may be present $\overparen{\Omega}$ with this because of insufficient binding material for the calcium.

There is undoubtedly a defective absorption of: $\vec{\circ}$ nitrogen, as shown by studies using yeast-protein $\overrightarrow{-}$ labelled with the heavy nitrogen isotope ${ }^{15} \mathrm{~N}$ (Crane ${ }^{\omega}$ and Neuberger, 1960). More important, in somę cases, is the endogenous loss of protein from the 3 . gastrointestinal tract. This has been assessed by using polyvinyl-pyrrolidone (PVP), a plasmaprotein substitute with a similar molecular weight ${ }_{+}^{+}$ to albumin, which is labelled with ${ }^{131} \mathrm{I}$. It is injected intravenously and passes into the alimen- 9 tary tract in the same way as albumin, but, being 음 metabolically inert, it is not digested, but can bemeasured in the fæces. This technique shows that large amounts of serum albumin may be passing $\mathbb{\Phi}_{\overparen{\Phi}}$ into the gut and so are lost to the body; sometimes the quantities are larger than in other cases $\frac{}{6}$ of protein-losing enteropathies (Schwartz aro Jarnum, I959; Parkins, I960; London, Bamfort and Creamer, 196r). It is interesting to speculape. whether this loss occurs in the intestinal juices, from capillary leakage into the gut, or because of a mucosal defect.

\section{Bone Disease}

The crippling deformities of the rickets of $\overrightarrow{\vec{F}}$ cœliac disease or the equivalent-osteomalacia-in 3 adults are fortunately seldom seen today and examples of bone disease usually masquerade under labels of 'fibrositis' or 'rheumatism'. 흘 Steatorrhœa is the commonest cause of osteomalacia in this country and in a recent series (Nordin, I96I) accounted for I I out of I 4 cases. The radiological picture is diagnostic when it $\frac{\rho}{2}$ shows 'pseudo-fractures'. These are slit-like

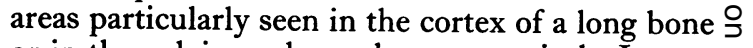
or in the pelvis, and may be symmetrical. Looser $\rightarrow$ (1920) called these areas ' zones of transformation '을. because they are not real fractures, and histological $/$ evidence show that they consist of non-calcified cells. They occur in areas where there are pulsat- 0 ing vessels or where there is stress (Fourman, $\tilde{\omega}$ I 960 ). The biochemical diagnosis is suggested by a reduction in the plasma calcium and especially the phosphate, and a rise in the alkaline phosphatase. Other methods of diagnosis have been $\stackrel{\mathscr{N}}{+}$ reviewed by Nordin (196I) who finds the four- $\frac{T}{0}$ hour calcium retention test (Findlay, Nordin and $\underset{\mathbb{D}}{\stackrel{\circ}{*}}$ 
Fraser, 1956) simple and reliable; injected calcium is retained in osteomalacia and the test is positive in the early stages. Iliac crest biopsy is rarely essential; and the calcium balance, a lengthy and costly procedure, is the only way of testing calcium absorption until an isotope method is available. Osteomalacia is due to lack of vitamin D. This may be due to defective absorption (Badenoch and Fourman, 1954) or to defective utilization resulting from some 'toxic action' of gluten (Nassim, Saville, Cook and Mulligan, 1959). The lowering of the serum calcium results in a stimulation of the parathyroid glands, so that parathormone releases calcium from the bones and maintains a satisfactory serum level but causes a lowering of the serum phosphorus due to loss of urinary phosphates. This hypothesis explains occasional cases where there are radiological signs of both osteomalacia and hyperparathyroidism in the same patient, and long-standing stimulation of the parathyroid glands may explain the parathyroid adenomata that are occasionally seen in these patients and which sometimes may need surgical removal (Davies, Dent and Willcox, 1956). If hyperparathyroidism is present, and glandular hypofunction is common in steatorrhœa, calcium is not mobilized from the bones, the serum calcium remains low, and tetany may develop.

Osteoporosis, an atrophy of the bone, is also seen in patients with idiopathic steatorrhœa, but steatorrhœa only accounts for about $15 \%$ of cases with osteoporosis (Nordin, I96r). It particularly affects the spine and pelvis resulting in diminished bone density and 'fish vertebræ' due to unhindered expansion of the intervertebral discs. The blood chemistry is normal. It is probably due to diminished calcium absorption. A long-continued negative calcium balance would result in the removal of mineral from the bone followed by the removal of matrix (Carttar, McLean and Urist, I950); this would reduce the bone mass without altering its mineral contents. The exact diagnosis of bone disease in steatorrhœea may be difficul tand in most patients osteoporosis and osteomalacia occur together.

\section{Neurological Manifestations}

Minor symptoms are not uncommon and resemble a peripheral neuropathy, with tingling and numbness in the extremities. This may happen in any severe anæmia but should direct the attention towards an early vitamin $B_{12}$ neuropathy. It should also be remembered that a sensation of numbness in the fingers, toes or lips may be an early sign of hypocalcæmia, and muscle weakness with absent tendon reflexes accompanies hypokalæmia. Serious neurological problems are rare, unlikely to occur in more than 2 or $3 \%$ of patients
(Cooke and others, 1953; Bossak, Wang and Adlersberg, 1957). A true peripheral neuropathy may occur, with a normal or raised protein in the cerebrospinal fluid and usually unresponsive to vitamin $\mathrm{B}_{1}$; or, rarely, a myelo-reticulo-neuropathy. The latter may be a progressive crippling disease which fails to respond to any known treatment, and corticosteroid drugs have seemed to make it worse (Adlersberg, 1957). The histology of the case described by Badenoch (I960) showed a generalized demyelination in the spinal cord with some sparing of the lateral columns. Occasionally the syndrome of subacute combined degeneration of the cord due to vitamin $B_{12}$ deficiency may occur but generally patients with idiopathic steatorrhœa seem unlikely to develop this in spite of their frequent low vitamin $B_{12}$ levels; nor have we found any convincing evidence that prolonged folic acid therapy precipitates these lesions, as in pernicious anæmia. Mental disturbances are unusual and factors such as dehydration, electrolyte loss, protein and other deficiencies may be important in causing these.

\section{Differential Diagnosis}

The diagnosis is still often one of exclusion and the various conditions that will pass through the physician's mind when he sees a patient with probable idiopathic steatorrhœa are listed in Table I. Structural diseases of the small intestine, often suggested by the presence of pain, should be excluded, as far as possible, by radiological studies. A stricture or localized diverticulosis is important to recognize as surgery may cure the condition; detection may be difficult and diverticula may either fail to fill or resemble the blobs of barium seen with the flocculation pattern. However careful are these and other studies, the most stringent test of all-the passage of time-will reveal an occasional case of a disease such as regional ileitis which has mimicked idiopathic steatorrhœa, and has escaped detection by every investigation.

One had hoped that jejunal biopsy would be the final court of appeal. This is probably so when the flat appearance of sub-total villous atrophy is present, though a superficial resemblance may be present in Crohn's disease (Rubin and others, 1960). The partial villous atrophy is not specific and can result from neomycin therapy. Characteristic and diagnostic appearances are seen in Whipple's disease (England, French and Rawson, I960), suspected in a middle-aged man with joint pains and sometimes enlarged glands; and also in amyloidosis. The rare and bizarre condition of acanthocytosis, or alpha-beta-lipoproteinæmia (Salt, Wolff, Lloyd, Fosbrooke, Cameron and Hubble, I960) has an equally curious appearance 
TABLE I

\section{Causes of Steatorrhoea}

The Small Intestine

Idiopathic steatorrhœa, cœline disease, and tropical sprue

Regional enteritis, either local or diffuse

Diverticulosis, blind loops, strictures, gastro-colic and other fistulæ

Whipple's disease

Systemic sclerosis

Amyloidosis

Tumours

Infections : Bacteria

Viruses

Tuberculosis

Giardia lamblia

Ischæmia from mesenteric occlusion or arteriosclerosis

Irradiation

Drugs: Antibiotics (neomycin)

Purgatives such as

Phenolphthalein

Phenindione (Dindevan)

The Pancreas

Pancreatitis

Carcinoma

Adult mucoviscidosis (cystic fibrosis)

Zollinger-Ellison syndrome

Chronic hepatitis

\section{The Liver}

Cirrhosis

Reticuloses

$$
\text { Mesenteric Lymphadenopathy }
$$

Tuberculosis

Diabetes mellitus

\section{General Disorders}

Thyrotoxicosis

Hypogammaglobulinæmia

Acanthocytosis

Congestive cardiac failure

of the jejunal mucosa, and occurs in young adults who have a very low serum cholesterol and spiky red cells. More mundane is infection with giardia lamblia; the parasites can sometimes be seen by special stains on the villi in children with the cœliac syndrome (Cameron and Rogers, 196r) and should be thought of in adults. A course of mepacrine is a diagnostic therapeutic test.

Disease of the pancreas usually does not present the clinical picture of idiopathic steatorrhœa as the macrocytic anæmia and sore tongue are lacking; bony damage may occur from defective absorption of calcium. The small intestine is normal by jejunal biopsy and usually there is no radiological change. Globules of neutral fat may be seen on microscopy of the stools, and duodenal aspiration following secretion shows deficient pancreatic enzymes. Occasional cases of adult mucoviscidosis (cystic fibrosis) are now being discovered, and this may be suspected in a young person with 'bronchiectasis' and long-standing steatorrhœa. Liver disease causes steatorrhœa (Gross, Comfort,
Wollaegar and Power, 1950), and this may be due to impairment of formation and secretion of bile salts rather than a quantative deficiency of bile. Recently, Moertel and Summerskill (196I) have described a typical malabsorption syndrome in unsuspected liver disease without jaundice. There was gross steatorrhœa with a flocculation pattern on barium meal X-ray, and defective absorption of vitamin $B_{12}$, fat-soluble vitamins and calcium; but with a normal jejunal biopsy. There was no hyperbilirubinæmia but liver-function tests and liver biopsy showed cirrhosis in three cases and $\vec{\circ}$ hepatitis in one. There was, in two, complete diappearance of the steatorrhœa with improvement in liver function. This interesting study further $\overparen{g}$ adds to the difficulty of diagnosis.

The function of every organ depends upon its blood supply and it is not surprising that steatorrhœa may follow mesenteric vascular occlusion or arteriosclerosis (Hawkins, 1957; Shaw and Maynard, 1958) and this may be suspected in the elderly. Various general diseases may be ac- $ᄋ$ companied by steatorrhœa but there is usually little difficulty about the correct diagnosis.

Tropical sprue is diagnosed solely by the fact that the patient develops the disease in the tropics. This indefinite distinction will be of less value as rapid travel from one part of the globe to anotheo increases. The acute florid sprue may sho clinical differences such as the severity of the or lesions and the frequency of megaloblastiv anæmia, and the lack of deficiencies of vitamin B, or calcium, but Baker (1957) has shown that a condition identical to idiopathic steatorrhœa occurs among the natives of South India if a proper history and investigations are carried out; further- $\overrightarrow{\vec{O}}$ more, tropical megaloblastic anæmia (nutritional megaloblastic anæmia) is usually due to steatorhœa (Baker, 1958). This indicates that the view that sprue occurs mainly amongst Europeans has to be altered. The jejunal biopsy appearance of 3 . tropical sprue is identical to that of many cases of idiopathic steatorrhœa, and shows a 'partial villous atrophy'. Perhaps trials of the gluten-free diet, $ᄋ$ which is ineffective in tropical sprue, may show that idiopathic steatorrhœea also occurs in the 의 tropics.

\section{The Role of Gluten}

Gluten, from the chemist's viewpoint, is a vague term applied to the tenacious, almost tasteless substance obtained by washing flour in water, in which $\underset{\omega}{N}$ it is soluble. There are several different types of gluten in nature and it is curious that wheat ando rye flour, which both cause deterioration in coliac $\Phi$ disease, also both make dough suitable for bread $\stackrel{\mathscr{C}}{\rightarrow}$ making; rice and maize, although containing ${ }^{0}$ gluten, can be taken by cœliac children without ill $\underset{\widetilde{ }}{\circ}$ 
effect, but do not make dough. Gluten contains a number of substances such as gluten casein, gliadin, glutin and mucedin. The gliadin is the noxious substance (Kamer and Weijers, 1955) and is a complex protein with an unusual amino-acid composition, and there is a low content of lysine, methionine and other amino-acids, but a high content of glutamine. Analytical studies and the testing of various products on cœliac children indicate that the toxic substance is probably an intermediate fraction, such as a polypeptide, rather than one of the amino-acids (Frazer, 1956), for complete hydrolysis of peptides to component amino-acids is followed by loss of toxic effect. Further work is likely to be slow. The chemistry is complex and the practical tests present difficulties, as they entail subjecting a child or adult who has regained health on a gluten-free diet to tests with these substances, preferably in hospital.

\section{The Specificity of Gluten Sensitivity}

Gluten sensitivity seems to be confined to cœliac disease and idiopathic steatorrhœa and gluten withdrawal has no effect in classical tropical sprue and pancreatic steatorrhœa. Weijers, Kamer and Vande (1959) noted a temporary wheat sensitivity in infants recovering from a serious nutritional disturbance, and this occurred in the phase where the intestine was still hypotonic. There have also been reports where the gluten-free diet was effective in other conditions, such as Crohn's disease, and post-gastrectomy steatorrhœa with hypoproteinæmia (Forshaw, 1958). It is perhaps well to remember that the history of gastroenterology abounds with reports of numerous intestinal disorders responding to a variety of diets. In proving gluten sensitivity it is first necessary to exclude a coincidental idiopathic steatorrhœe by jejunal biopsy; and, secondly, to show that a relapse can be induced by giving gluten to the patient again after the apparent cure on the gluten-free diet.

\section{The Effect of Gluten upon the Intestinal Mucosa}

This distant organ, unlit, as Avery Jones remarked, by the endoscopy light, is difficult to investigate from this aspect. Some new evidence has appeared from the use of biopsy tubes, which take several specimens of mucosa simultaneously from different levels of the small bowel. The main lesion in idiopathic steatorrhoa is in the jejunum, but, according to Rubin (196r), this may extend distally into the ileum for variable distances. He studied patients on a gluten-free diet where the ileum was normal by instilling $50 \mathrm{~g}$. of wheat directly into the ileum (Rubin, Brandborg, Flick, Parmentier, Phelps and Van Niel, I960). This not only produced constitutional effects with diarrhœa, but caused changes in the ileal mucosa similar to those seen in the jejunum; in one case it caused malabsorption of vitamin $B_{12}$, which persisted for many months. It appeared that the normal ileal mucosa could be severely damaged within six hours, but the histological changes might disappear within the same period. None of these effects occurred in healthy controls. Such results indicate a direct toxic effect upon the mucosa and may open a new avenue of research.

\section{The Evidence of Allergy to Gluten}

Allergy is suspected by the occasional sudden and severe relapse when gluten is given to the patient who has responded successfully to the gluten-free diet. Generally, however, patients do not develop symptoms till from 10 days to three weeks following the reintroduction of this into their diet and the symptoms usually start gradually. It might be argued that the probable excess of mucus in the small bowel, as indicated by the flocculation of barium, is a sign of an allergic reaction and the beneficial effects of corticosteroid therapy would accord with this theory. The fact that various skin tests are negative to gliadin and other compounds (Kamer and Weijers, 1955; Sheldon, I955) does not exclude it. Some workers (Frazer, Fletcher, Ross, Shaw, Sammons and Schneider, 1959) claim to have prepared an enzymatic metabolite of gluten which has been autoclaved, a process that results in a fraction free from antigenic properties, but with the same deleterious effect. This does not exclude a local reaction due to an immuno-chemical process, apart from allergy.

\section{An Enzyme Defect}

It is postulated that, owing to a defective enzyme system in the cell, the small intestine is unable to handle the gluten molecule properly. An intermediate metabolite, such as a polypeptide, is then able to enter the blood stream or lymphatics. Some support was given to this from the results of feeding gliadin to healthy children and to those with cœliac disease (Weijers and others, 1959). A substance, probably a glutamine peptide, was measured in the blood and tolerance curve formed. The levels in the children with cœliac disease were much higher than in those with normal controls. Unfortunately, the results are variable and make this procedure useless as a diagnostic test (Alvey, Anderson and Freeman, 1957). It might be further argued that the toxic substance might not only affect the blood, the liver, the CNS and elsewhere, but also damage the intestinal mucosa itself. It is certainly interesting, from the clinical aspect, that the child starts to grow on a gluten-free diet before there is any change in intestinal function and fat absorption (Sheldon, 1955), suggesting the 
sudden cessation of some toxic effect on growth. Similarly, in the severe megaloblastic anæmia a reticulocytosis and a rise in the blood cells begins immediaetly after withdrawal of gluten and before any changes occur in the fæcal fat excretion. Finally, some patients with osteomalacia are highly resistant to the action of vitamin $\mathrm{D}$ until gluten is withdrawn; resistance again occurs when gluten is reintroduced into the diet (Nassim, Saville, Cook and Mulligan, 1959). A disease due to a toxic intermediate metabolite because of incomplete breakdown of a substance from a defective enzyme system is not new to medicine and typical examples are phenylketonuria and alkaptonuria.

\section{The Cause of Failure of Patients to Respond to the Gluten-free Diet}

The gluten-free diet is successful in about $70 \%$ of patients, and the failures are indistinguishable, either clinically or at autopsy (French, Hawkins and Smith, I957), from those which are cured. The cause of the failures is unknown. Perhaps the ætiology is different, or a protein other than gluten is responsible. The problem of attempting to find another toxic substance by elimination diet is great; the discovery of the deleterious effect of bread was a brilliant clinical observation facilitated by a particular set of circumstances. There is no correlation between the severity of the biopsy appearance and the clinical response, but Rubin (I96I) has suggested a relation between response and the extent of the lesion in the small intestine. It is possible that successful cases may show changes in the jejunum only, whereas failures may have abnormalities in the mucosa of the ileum as well.

\section{The Cause of Malabsorption}

The precise defect in the intestinal cell which prevents proper absorption is unknown, but the faulty development of the villi must decrease the surface area very considerably. It is the more remarkable that such marked gains in weight are seen although the mucosal appearance remains unchanged.

Once a primary defect of absorption has occurred, it is possible that secondary factors further decrease transportation of food across the intestinal mucosa. The fact that the small bowel is dilated and movement depressed may hinder absorption. The absorption of both glucose and methionine can be improved in normals and in patients with steatorrhœa by increasing the motility of the bowel wall (Cummins and Almy, 1953); similarly the absorption of heavy water and radioactive sodium is reduced in normals following the injection of methantheline bromide (banthine) (Higgins, Code and Orvis, 1956). This has been attributed to reduction in the area of absorbing surface to which ڤำ these substances are exposed because of the $\frac{\pi}{\infty}$ hypomotility of the bowel. The probable excess of 은 mucus in the small bowel in idiopathic steatorrhoa may form a mucus-barrier to absorption, and the small bowel, being full of undigested food products, $\overline{0}$ may become secondarily infected with bacteria, a 흠 probability that explains the occasional improvement in absorption noted by antibiotics. Finally, the bowel is distended with fluid contents, the increased volume being due to delayed absorption ${ }^{\infty}$ of water. This would not only dilute the essential $\vec{\circ}$ nutrients, but give the individual villus less $\overrightarrow{\vec{\omega}}$ opportunity to come into contact with the main $\stackrel{\omega}{\omega}$ stream of intestinal contents. The more dilated the $\overline{0}$ gut, the greater the ratio of intestinal volume to 3 absorptive surface. Perhaps there is an analogy with respiratory function and that the large quantity of fluid contents acts as a dead space and $\underset{+}{+}$ the hypotonic bowel wall may behave similarly

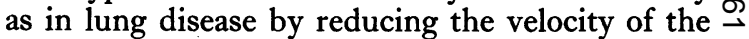
flow.

\section{Treatment}

\section{The Gluten-free Diet}

This is so effective in many cases (French and others, 1957) that almost every patient should be $\Phi$ given a trial on the diet. One is naturally reluctarg to deprive anyone of the pleasures of the table but even the mild cases may develop a sense well-being that they have not experienced before. Also, the patients are safer when gluten is eliminated, for the condition is potentially dangerous with a higher mortality than in peptic ulcer, a condition where the sufferers are deprived $\triangle$ of their food for long periods with no objective proof of any benefit. Response to the gluten-free diet is noted by the colour of the stool returning to normal, the diarrhœa disappearing and even constipation developing; an important sign is an increase in weight. The fat absorption returns to normal, and later the small intestine appears normal on X-ray. Megaloblastic anæmia responds to withdrawal of gluten without any hæmatinics; the reticulocyte response and rise in red cells is similar to the effect of folic acid but occurs over a more prolonged period, and the marrow reverts to normal in about a month. The blood chemistry (Schwartz, Sleisenger, Pert, Roberts, Randall and No Almy, 1957) including the serotonin levels (Pimparkar, Senesky and Kalsar, I96I) returns to normal and iron is absorbed satisfactorily $\omega$ (Badenoch and Callendar, 1960). The histology of the mucosa may not change and often the folic 0 acid absorption tests may still remain abnormal. $\mathbb{D}$ Complete proof of gluten sensitivity is obtained when a relapse is induced by giving gluten powder or putting the patient on a normal diet for a short 
period. Practical details of the diet have been given before in this journal (Hawkins, 1955) and a particularly useful study of the gluten contents of manufactured foods was reported by Fletcher and McCricick (1958); these workers pointed out that additional milk and vitamins may be needed in growing children as flour normally supplies protein, calcium, iron, thiamine, and nicotinic acid.

It is to be expected that about $70 \%$ of patients will respond to the diet, and, to the moment, Dr. J. M. French and I find that 34 out of 48 cases have reacted successfully.

\section{Corticosteroid Therapy}

Corticosteroid drugs improve the function of the small intestine in idiopathic steatorrhœa (Taylor, Wollaeger, Comfort and Power, I952; Cooke, 1953; Adlersberg, 1957). An increase in fat absorption is noted within 36 hours and figures may almost reach normal levels, but relapse takes place immediately the treatment is stopped so that the fat excretion is the same or sometimes worse. The patient may even become constipated with hard stools, an indication of improved water absorption. There may be sodium and potassium retention, a positive nitrogen balance, restoration of a prolonged prothrombin time to normal levels, and an increase in the serum albumin, calcium, and fasting carotene. The absorption of radioactive iron is improved, sometimes to within the high levels seen in simple iron-deficient anæmia (Badenoch and Callendar, I960), an effect that is not seen in normals. Oral treatment with cortisone or prednisone is preferable to corticotrophin and a dose of $100 \mathrm{mg}$. of cortisone daily or the equivalent amount of prednisone can be given for seven to ten days, following which the dose can gradually be reduced until the minimum necessary to alleviate symptoms; this may be as low as $15 \mathrm{mg}$. of cortisone or $5 \mathrm{mg}$. of prednisone daily. A particular concern in these patients is the risk of osteoporosis and spontaneous fractures. The results of calcium and phosphate balances, on a short-term basis, are rather indefinite (Taylor and others, I952) but in one patient, the spontaneous fracture was actually healed when the patient was put on corticosteroid treatment. But, although the shortterm effects on calcium metabolism may be reassuring, the long-term effects are probably similar to patients with a normal intestine, and any osteoporosis may be aggravated. It would probably be wise to keep this treatment as a temporary measure for the acutely ill case and to use it for longer periods only in the severe intractable patient who has failed to respond to the gluten-free diet and other measures. It is interesting to speculate how intestinal absorption is improved. The histology of the intestinal mucosa remains unchanged and its effect is seen in patients who have had no gluten for long periods, so that it does not act through the mechanism underlying gluten sensitivity. Perhaps it may improve the enzyme function of the cell itself, an effect that perhaps may in the future be seen by histochemical studies with the electron microscope.

\section{Antibiotics}

Antibiotics play no part in the routine treatment, for the drugs themselves may cause both diarrhœa and steatorrhœa. Yet one undoubtedly sees an occasional patient who benefits. This may occur when there has been little if any response to the exclusion of gluten; then, a short course of a wide range antibiotic may result in a definite improvement with a sudden increase in weight, but this is the exception rather than the rule. This has been proved objectively by French (196r) who has shown a temporary improvement in fat absorption, with reversion to the pre-treatment level if the drug is stopped. The most likely explanation is that the small bowel of some patients become contaminated with bacteria but there is no means, at present, of detecting when this occurs.

\section{Treatment of the Patients who fail to Respond to the Gluten-free Diet}

Simple non-specific measures are effective in keeping about $70 \%$ of these patients in a reasonable state of health (Cooke, 1952). A diet high in protein, usually 100 to $120 \mathrm{~g}$. and low in fat, $50 \mathrm{~g}$. or less, is prescribed. Calcium salts have been used for many years in sprue and a constipating effect may be obtained by the following mixture: calcium phosphate 2 g., calcium lactate 2 g., calcium carbonate $2 \mathrm{~g}$. This is prescribed as a powder and $6 \mathrm{~g}$. or more is taken three times daily or as often as is necessary; some patients like to keep the powder available and take it whenever the diarrhœa becomes troublesome. The rationale is that these calcium salts, with varying solubility, react with the irritant fatty acids at different levels of the bowel and form non-irritating calcium soaps. Multiple vitamin deficiencies are so common that idiopathic steatorrhœa provides one of the few rational indications for shot-gun therapy (Badenoch, 1960). These patients might therefore be given an assortment of vitamin tablets, folic acid, iron, vitamin $B_{12}$ and so on. However, this will often be unnecessary and one's prescribing is tempered by the knowledge that few patients are likely to take drugs regularly and conscientiously. The better policy is to see them regularly at a follow-up clinic, at three- or six-monthly intervals and to check their blood count and blood chemistry and to prescribe when the need arises; otherwise a false sense of security may be given. 


\section{Prognosis}

The mortality rate before the advent of the gluten-free diet was from 14 to $20 \%$ (Cooke and others, 1953; Bossak and others, 1957). Causes of death (Hines and Adlersberg, 1957) were: bowel hæmorrhage from vitamin $\mathrm{K}$ deficiency, volvulus of the sigmoid colon, respiratory and other infections to which these patients are more liable, and tuberculosis. The gluten-free diet has greatly improved the prognosis but not all patients are gluten-sensitive, and deaths still occur. One recently-described cause is hypothermia (Dent,
Stokes and Carpenter, 196I), a complication that is missed with the ordinary clinical thermometero which does not register below $95^{\circ} \mathrm{F}$. $\left(35^{\circ} \mathrm{C}\right.$. $) \cdot \stackrel{\mathrm{C}}{\mathrm{C}}$ Other cases may go slowly and relentlessly down $=$ hill for no known reason, and the negative findings? at autopsy are a striking contrast to the signs ofo the terminal illness. The fatal outcome may then be attributed to 'Inanition', a term which merely conceals an ignorance of the metabolic processes $\_$ causing death. So, from the beginning to the end, we really do not know; but, to say that we do notknow, is surely the beginning of wisdom.

\section{REFERENCES}

Adlersberg, D. (1957): Adrenal Steroids in Treatment of Malabsorption Syndrome, Med. Clin. N. Amer., 41, I597. , Wang, C. I., and BossaK, E. T. (1957): Disturbances in Protein and Lipid Metabolism in Malabsorption Syn drome, F. Mt Sinai Hosp., 24, 206.

Alvey, C., Anderson, 'C. M., and Freeman, M. (1957): Wheat Gluten and Coliac Disease, Arch. Dis. Childh., 32, 434:A

Anderson, B., Belcher, E. H., Chanarin, I., and Mollin, D. L. (1960): The Urinary and Fæcal Excretion of Radio- + activity after Oral Doses of $\mathrm{H}^{3}$-Folic Acid, Brit. F. Hamat., 6, 439.

ANNEgers, J. H., Boutwell, J. H., and Ivy, A. C. (1948): The Effect of Dietary Fat on Fecal Fat Excretion andô Subjective Symptoms in Man, Gastroenterology, 1o, 486.

Ardran, G. M., French, J. M., and Mucklow, E. H. (1950): Relationship of the Nature of the Opaque Medium to음 Small Intestine Radiographic Pattern, Brit. F. Radiol., 23, 697.

BadenOCH, J., and Fourman, P. (1954): Osteomalacia in Steatorrhoea, Quart. F. Med., N.S. 23, 165.

(1960): Steatorrhoa in the Adult, Brit. med.. ., ii, 879 . Steatorrhœa and Cœliac Disease, Lancet, $\mathbf{i}, \mathbf{1} 92$.

BAKER, S. J. (1957): Idiopathic Tropical Steatorrhœea. A Report of Sixty Cases, Indian F. med. Sci., 2, 687.

- (1958): Tropical Megaloblastic Anæmia in South India, Indian Y. Path. Bact., I, I 1 .

, and Hughes, A. (1960): Multiple-retrieving Small-intestinal Biopsy Tube, Lancet, ii, 686. Absorption Test in Malabsorption Syndromes, New. Engl. F. Med., 256, 335.

Bossak, E. T., WANG, C. I., and AdLersBerg, D. (1957): Clinical Aspects of Malabsorption Syndrome (Idiopathe Steatorrhœa): Observations in 94 Patients, F. Mt Sinai Hosp., 24, 286.

BRAdLeY, J., and CoOKE, W. T. (1960): Personal communication.

Brandborg, L. L., Rubin, C. E., and Quinton, W. E. A. (1959): A Multipurpose Instrument for Suction Biopsy of the Esophagus, Stomach, Small Bowel and Colon, Gastroenterology, 37, r.

Butterworth, C. E., JR., Nadel, H., Perez-Santiago, E., Santini, R., and Gardner, F. H. (1957): Folic Acid@ Absorption, Excretion, and Leukocyte Concentration in Tropical Sprue, F. Lab. clin. Med., 50, 673.

, and Perez-Santiago, E. (1958): Jejunal Biopsies in Sprue, Ann. intern. Med., 48, 8.
Cameron, A. H., and Rogers, K. B. (196r): Non-specific Jejunitis in Children and its Relation to Giardia Lamblia, F. clin. Path., 14; 329.

Carter, F. C., Heller, P., SchaffNer, G., and Korn, R. J. (196r): Formiminoglutamic Acid (FIGLU) Excretion ino Hepatic Cirrhosis, Arch. intern. Med., 108, 4I.

CartTar, M. S., McLean, F. C., and Urist, M. R. (1950): The Effect of the Calcium and Phosphorus Content of the Diet upon the Formation and Structure of Bone, Amer. F. Path., 26, 307.

Chanarin, I., Mollin, D. L., and Anderson, B. B. (I958): The Clearance from the Plasma of Folic Acid Injected Intravenously in Normal Subjects and Patients with Megaloblastic Anæmia, Brit. F. Hamat., 4, 435.

-, ANDERson, B. B., and Mollin, D. L. (1958): The Absorption of Folic Acid, Ibid., 4, 156.

Christiansen, P. A., Kirsner, J. B., and Ablaza, J. (1959): d-Xylose and its Use in Diagnosis of Malabsorption States, Amer. F. Med., 27, 443.

Cooke, T. W. (I953): The Effect of Corticotrophin in Idiopathic Steatorrhœa, Lancet, ii, 425.

, PEeney, A. L. W., and Hawkins, C. F. (1953): Symptoms, Signs and Diagnostic Features of IdiopathicD

Steatorrhoa, Quart. F. Med., 22, 59.
(1957): Water and Electrolyte Upsets in the Steatorrhœa Syndrome, F. Mt Sinai Hosp., 24, 22 I.

(I952): 'Modern Trends in Gastroenterology'. Ed. F. A. Jones. London: Butterworth.

Cox, E. The Folic Acid Excretion Test in the Steatorrhoe

Syndrome, Gastroenterology, 35, 390.
CRANE, C. W., and NeUBERGER, A. (1960): Absorption and Elimination of ${ }^{15} \mathrm{~N}$ after Administration of Isotopically Labelled Yeast Protein Hydrolysate to Adult Patients with Coliac Disease, Brit. med. F., ii, 888.

Crossby, W. H., and Kugler, H. W. (1957): Intraluminar Biopsy of the Small Intestine, Amer. F. dig. Dis., 2, 236. Cummins, A. J., and Almy, T. P. (1953): Studies on the Relationship between Motility and Absorption in the Humare Small Intestine, Gastroenterology, 23, 179.

Davies, D. R., DenT, C. E., and Willcox, A. (1956): Hyperparathyroidism and Steatorrhœa, Brit. med. F., ii, I 133. DENT, C. E., STOKES, J. F., and CARPENTER, M. E. (196I): Death from Hypothermia in Steatorrhœa, Lancet, $\mathbf{i}, 748$. DoIg, A., and GirDwood, R. H. (1960): The Absorption of Folic Acid and Labelled Cyanocobalamin in Intestina Malabsorption, Quart. $\mathcal{F}$. Med., N.S. 29, 333. 
England, M. T., French, J. M., and Rawson, A. B. (1960): Antibiotic Control of Diarrhoea in Whipple's Disease, Gastroenterology, 39, 219.

Fairley, N. H., and MAckie, F. P. (1937): A Clinical and Biochemical Syndrome in Lymphadenoma and Allied Diseases Involving the Mesenteric Lymph Glands, Brit. med. $\mathcal{F} .$, i, 375.

Falcon, W. W., and JACOBSON, E. D. (196r): Malabsorption During Neomycin Administration, Gastroenterology, 40, 447 .

Findlay, J. M., Nordin, B. E. C., and Fraser, R. (1956): A Calcium Infusion Test. ' Four-Hour Skeletal Retention' Data for Recognition of Osteoporosis, Lancet, i, 826 .

Flear, C. T. G., Cooke, W. T., and Quinton, A. (1959): Water Diuresis and Steatorrhœe, Clin. Sci., 18, 137.

Fletcher, R. F., and McCricick, M. Y. (1958): Gluten-free Diets, Brit. med. F., ii, 299.

Fone, D. J., Meynell, M. J., Harris, E. L., Cooke, W. T., Brewer, D. B., and Cox, E. V. (1960): Jejunal Biopsy in Adult Coeliac Disease and Allied Disorders, Lancet, i, 933.

Forshaw, J. W. B. (1958): Hypoproteinæmia after Partial Gastrectomy Corrected by Gluten-free Diet, Brit. med. F., ii, 1020 .

Fourman, P. (1960): ' Calcium Metabolism and the Bone'. Oxford: Blackwell.

Fowler, D., and COOKE, W. T. (1960): Diagnostic Significance of d-Xylose Excretion Test, Gut, r, 67.

Frazer, A. C. (1956): Discussion on Some Problems of Steatorrhœa and Reduced Stature, Proc. roy. Soc. Med., 49, I009.

- - Fletcher, R. F., Ross, C. A. C., Shaw, B., Sammons, H. G., and Schneider, R. (1959): Gluten-induced Enteropathy: Effect of Partially Digested Gluten, Lancet, ii, 252.

French, J. M., Hawkins, C. F., and Smith, N. (1957): The Effect of a Wheat-Gluten-free Diet in Adult Idiopathic Steatorrhœa, Quart. F. Med., N.S. 26, 48 r.

(1961): Problems Raised by the Treatment of Steatorrhœea with Antibacterial Drugs, Postgrad. med. F., 37, 259.

Gaddie, R., Thomas, G., Smith, N., and French, J. M. (1957): The Value of the Oral Glucose Tolerance Test in the Diagnosis of Pancreatic from Idiopathic Steatorrhœe, Quart. F. Med., N.S. 26, 121.

Gardner, F. H. (1956): A Malabsorption Syndrome in Military Personnel in Puerto Rico, A.M.A. Arch. intern. Med., 98, 44 .

GirDWOod, R. H. (1953): Folic Acid Excretion Investigation of Intestinal Malabsorption, Lancet, ii, 53. (1960): Diagnosis of Megaloblastic Anæmias, in 'Lectures on Hæmatology '. Ed. Hayhoe, F. G. J. London: Cambridge University Press.

Glass, G. B. J. (1956): Intestinal Absorption and Hepatic Uptake of Vitamin $B_{12}$ in Diseases of the Gastrointestinal Tract, Gastroenterology, 30, 37 .

Green, P. A., and Wollaeger, E. E. (1959): ' The Clinical Behaviour of Sprue in the United States'. Symposium: Malabsorption Syndrome. World Congress of Gastroenterology, Washington. Vol. I, 1958, p. 558. Baltimore: Williams and Wilkins.

Gross, J. B., Comfort, M. W., Wollaeger, E. E., and Power, M. H. (1950): Total Solids, Fat and Nitrogen in the Feces: V. A Study of Patients with Primary Parenchymatous Hepatic Disease, Gastroenterology, 16, 140.

Hawkins, C. F. (1955): The Treatment of Steatorrhoa, Postgrad. med. F., 31, 552.

(1957): Jejunal Stenosis Following Mesenteric Artery Occlusion, Lancet, ii, 121. , and Meynell, M. J. (1958): Macrocytosis and Macrocytic Anæmia Caused by Anticonvulsant Drugs, Quart. f. Med., N.S. 27, 45 .

Herbert, J. (196I): Assay of Folic Acid in Serum, f. clin. Invest., 40, 81.

Higgins, J. A., Code, C. F., and Orvis, A. L. (1956): The Influence of Motility on the Rate of Absorption of Sodium and Water from the Small Intestine of Healthy Persons, Gastroenterology, 31, 708.

Hines, H. W., and Adlersberg, D. (1957): Pathologic Studies in Idiopathic Sprue, $\mathcal{F}$. Mt. Sinai Hosp., 24,25 I.

INGeLfinger, F. J. (1943): The Diagnosis of Sprue in Non-Tropical Areas, New Engl. Y. Med., 228, 180.

Jacobson, E. D., PrioR, J. T., and Faloon, W. W. (I 960): The Malabsorption Syndrome Induced by Neomycin with Morphological Alterations in the Jejunal Mucosa, F. Lab. clin. Med., 56, 245.

Kamer, J. H. van DE, Huinink, H., Ten Bokkel, and WeIJers, H. A. (I949): Rapid Method for the Determination of Fat in Feces, $\mathcal{Y}$. biol. Chem., 177, 347.

- and WeIJERS, H. A. (1955): Coliac Disease: Some Experiences on the Cause of the Harmful Effect of Wheat Gliadin, Acta Padiat., 44, 465.

London, D. R., Bamford, J., and Creamer, B. (1961): Steatorrhœa Presenting with Gastrointestinal Protein Loss, Lancet, $\mathrm{ii}, \mathrm{I} 8$.

LOOSER, E. (1920): Uber Pathologische Formen von Infarktionen and Callusbildungen bei Rachitis und Osteomalakie und Anderen Knochen Erkrankungen, Zbl. Chir., 47, 1470.

McInTyre, P. A., Sachs, M. V., Krevans, J. R., and CoNley, C. L. (1956): Pathogenesis and Treatment of Macrocytic Anæmia, A.M.A. Arch. intern. Med., 98, 541.

Marshak, R. H., and Eliasoph, J. (1957): The Roentgen Findings in the Malabsorption Syndrome, Med. clin. N. Amer., p. 1565 .

Meynell, M. J., Cooke, W. T., Cox, E. V., and Gaddie, R. (1957): Serum Cyanocobalamin Levels in Chronic Intestinal Disorders, Lancet, i, 9or.

Moertel, C. G., and Summerskill, W. H. J. (196I): Malabsorption Syndrome Associated with Anicteric Liver Disease Gastroenterology, 40, 687 .

Mollin, D. L., and Ross, G. I. M. (1954): Vitamin B 12 Deficiency in the Megaloblastic Anæmias, Proc. roy. Soc. Med., 47, 428.

-, Booth, C. C., and Baker, S. J. (1957): The Absorption of Vitamin $B_{12}$ in Control Subjects in Addison's Pernicious Anæmia in the Malabsorption Syndrome, Brit. F. Hamat., 3, 412.

Moore, F. D., Edelman, I. S., Olney, J. M., James, A. H., Brooks, L., and Wilson, G. M. (1954): Body Sodium and Potassium 3. Lack of Correlation Between Body Stores and Plasma Concentration, Metabolism, 3, 334.

Moyer, J. H., and Womack, C. R. (1950): Glucose Tolerance Tests. Relative Validity of Four Different Types of Tests, Texas F. Med., 46, 763 . 
Nassim, J. R., Saville, P. D., Cook, P. B., and Mulligan, L. (r959): The Effects of Vitamin D and Gluten-free Diet in Idiopathic Steatorrhœa, Quart. F. Med., N.S. 28, 141 .

Newsholme, G. A., and French, J. M. (1954): Absorption of ${ }^{24} \mathrm{NaCl}$ from the Small Intestine: The Sprue Syndrome, $\stackrel{\mathbb{Q}}{\Omega}$ Clin. Sci., 13, 607.

Nordin, B. E. C. (196r): The Effects of Malabsorption Syndrome on Calcium Metabolism, Proc. roy. Soc. Med. $54,78$.

Parkins, R. A. (1960): Protein-losing Enteropathy in the Sprue Syndrome, Lancet, ii, 1366.

Pimparkar, B. D. Tulskey, E. G., Kalser, M. H., and Bockus, H. L. (1960): Correlation of Radioactive and Chemical Fæcal Fat in Different Malabsorption Syndromes, Brit. med. F., ii, 894.

- Senesky, D., and Kalsar, M. H. (1961): Blood Serotonin in Non-Tropical Sprue, Gastroenterology, $40,504$.

Reitemeier, R. J., Higgins, J. A., Lee, P. R., and Scholer, J. R. (r956): The Absorption of Water and Sodium from the Small Bowel of Patients with Non-Tropical Sprue, $\mathcal{F}$. clin. Invest., 35, 730.

Rubin, C. E., Brandborg, L. L., Flick, A. L., Parmentier, C., Phelps, P., and Van Niel, S. (ig6o): The Effect of @ Wheat Instillation into the Proximal Ileum in Patients with Idiopathic Sprue, $\mathcal{F}$. clin. Invest., $39,1023$.

- - - Phelps, P. C., and TAYlOR, H. C. ( 1960$)$ : Studies of Cœliac Disease, Gastroenterology, $38,28$.

- - - - - Murray, A. B., STEmler, R., Howry, C., and Volwiler, W. ( I 960): Studies of Cœliac Disease. II. The Apparent Irreversibility of the Proximal Intestinal Pathology in Coliac Disease, Gastroenterology, 38, 51 7. (I96I): Malabsorption: Cœliac Sprue, Ann. Rev. Med., 12, 39.

Salt, H. B., Wolff, O. H., Lloyd, J. K., Fosbrooke, A. S., Cameron, A. H., and Hubble, D. V. (i 960 ): On Having No Beta-Lipoprotein: A Syndrome Comprising Lipoproteinæmia, Acanthocytosis and Steatorrhœa, Lancet, ii, 325. 3

Santini, R., JR., Sheehy, T. W., and Martinez, DE J. J. (196i): The Xylose Tolerance Test with a Five-Gram Dose, $\dot{c}^{\circ}$ Gastroenterology, 40, 772.

Schwartz, M. K., Sleisinger, M. H., Pert, J. H., Roberts, K. E., Randall, H. T., and Almy, T. P. (i 957): Effect of i Gluten-free Diet on Fat, Nitrogen and Mineral Metabolism in Patients with Sprue, Ibid., 32, 232.

- and JARNUM, S. (1959): Gastrointestinal Protein Loss in Idiopathic (Hypercatabolic) Hypoproteinæmia, Lancet, i, 327.

Shaw, R. S., and Maynard, E. P. (1958): Acute and Chronic Thrombosis of the Mesenteric Arteries Associated with 0 Malabsorption, New Engl. F. Med., 258, 874.

Sheldon, W. (1955): Cœliac Disease, Lancet, ii, ro97.

Shiner, M. (1956): Jejunal Biopsy Tube, Ibid., i, 85 .

- and DoNIACH, I. (1959): 'Histopathologic Studies in Steatorrhœa', World Congress of Gastroenterology, Washington, 1958, i, 586. Baltimore: Williams and Wilkins.

Spray, G. H., and WitTs, L. J. (1959): Excretion of Formiminoglutamic Acid as an Index of Folic Acid Deficiency, Lancet, ii, 702.

Streeten, D. H. P., and Williams, E. M. (1952): Loss of Cellular Potassium as a Cause of Intestinal Paralysis in Pige F. Physiol., I18, 149.

Taylor, A. B., Wollaeger, E. E., Comfort, M. W., and Power, M. H. (1952): The Effect of Cortisone on Noris tropical Sprue (Idiopathic Steatorrhœa), Gastroenterology, 20, 203.

Waters, A. H., Mollin, D. L., Pope, J., and Towler, T. (196r): Studies in the Folic Acid Activity of Human Serum, F. clin. Path., 14, 335 .

Weijers, H. A., and Kamer, J. H. van DE (1959): 'Some Biochemical Investigations into the Cause of Wheat Sensitivity in Cœliac Disease', World Congress of Gastroenterology, Washington, 1 958, 1, 578. Baltimore: Williams and Wilkins.

Wenger, J., Kirsner, J. B., and Palmer, W. L. (1957): Blood Carotene in Steatorrhœa and Malabsorptive Syndromes, Amer. F. Med., 22, 373 .

Wollaeger, E. E., and Scribner, B. H. (195I): Delayed Excretion of Water with Regular Nocturnal Diuresis in Patients with Non-Tropical Sprue (Idiopathic Steatorrhœa), Gastroenterology, 19, 224.

Yudkin, S. (I94I): Estimation of Vitamin A and Carotene in Human Blood, Biochem. F., 35, 55 I. 